Tropical Journal of Pharmaceutical Research June 2012; 11 (3): 477-483

(C) Pharmacotherapy Group,

Faculty of Pharmacy, University of Benin

Benin City, 300001 Nigeria.

All rights reserved.

Available online at http://www.tjpr.org

Research Article

http://dx.doi.org/10.4314/tjpr.v11i3.18

\title{
Attitudes of Emergency Department Staff towards the Role of Clinical Pharmacists in a Region of Saudi Arabia - A Pilot Study
}

\author{
Tahir M Khan ${ }^{1 *}$, Chohan M Shahzad ${ }^{1}$, Mueen KK Ahmed ${ }^{1}$ and Saira \\ Azhar $^{2}$ \\ ${ }^{1}$ College of Clinical Pharmacy, King Faisal University, PO Box 400, Al-Ahsa, Kingdom of Saudi Arabia, ${ }^{2}$ Department \\ of Pharmacy, COMSAT, Abbottabad, Pakistan.
}

\begin{abstract}
Purpose: To evaluate the attitudes and perceptions of medical doctors and nurses in the Emergency Department ED towards the role of clinical pharmacists.

Methods: A pilot study was conducted among the medical and paramedical staff of the ED of Public Hospital, Eastern Region, Saudi Arabia, Al-Ahsa, using a 24-item questionnaire on Doctor of Pharmacy (Pharm-D) program as well as clinical pharmacist and medical staff attitudes toward the availability and possible role of clinical pharmacist in EDs. The data analysed statistically.

Results: Sixteen of the 20 respondents expressed a willingness to participate in the study. Six (37.5\%) of the respondents were doctors while the rest were nursing staff. Ten (62.5\%) of the ED staff were aware of the professional degree held by clinical pharmacists (i.e., Pharm-D), and a majority, 12 (75.0 $\%)$ had heard of a health care professional called a clinical pharmacist. While exploring medical staff attitude toward the availability of a full-time pharmacist in EDs, 13 (81.3\%) of the respondents viewed this favorably while that regarding the role of pharmacists in drug adherence and patient care was viewed less favorably. Fourteen (87.5\%) disagreed with giving prescription rights to clinical pharmacists for minor ailments.

Conclusion: These findings highlight the need to enhance the interaction between the medical and paramedical staff on the one hand, and the clinical pharmacist on the other. Clinical pharmacists need to be given an opportunity to prove their capabilities in direct patient care in order to facilitate the full participation of future Pharm- $D$ graduates in direct patient care in the Saudi health care system.
\end{abstract}

Keywords: Clinical pharmacist, Medical staff, Emergency department, Direct patient care, Saudi Arabia.

*Corresponding author: Email: tahir.pks@gmail.com 


\section{INTRODUCTION}

Clinical pharmacists are an essential part of the health care team, especially because they promote the safe and rational use of medications [1]. The typical role of clinical pharmacists involves ensuring appropriate prescription/therapeutic combinations and administration of the right medicine to the right patient in the appropriate dose via the proper route of administration. Other essential responsibilities of the clinical pharmacist are to monitor patient adherence to therapy, provide drug information, monitor patient responses and laboratory values, and provide patient and provider education. In increasing patients' adherence to therapy, clinical pharmacists simultaneously decrease the chances of drug-related problems, and in doing so, the patient's quality of life is enhanced and further economic burdens due to drug-related problems are lessened [2].

However, clinical pharmacists seldom play an effective role in the emergency department (ED) of Public Hospital, Al-Ahsa, Eastern Region, Saudi Arabia [2]. This may be due to the unique and complex nature of the ED. EDs in hospital settings are known to be high risk environments, with frequent emergency errors [3]. According to the findings of the U.S. Institute of Medicine, ED has the highest rate of preventable adverse events [4]. In the U.S., ED care is available to approximately 110 million patients per year [5]. Of these, 5.5 million (5\%) experience adverse drug events [6]. Studies have shown that $70 \%(3.8$ million) of these adverse drug events can be prevented through proper screening while administering and prescribing drugs to patients attending EDs [7]. Published reports on the incorporation of clinical pharmacists in the ED have shown a marked decline in the number of preventable iatrogenic errors with patients [8].

Al-Olah and $\mathrm{Al}$ Thiab reported a high incidence of drug related problems (DRPs) in the ED of a public hospital in Riyadh, Saudi Arabia. Over a duration of one month, approximately 557 patients visited the ED and $82(14.7 \%)$ of the patients experienced a DRP [9]. Admission to ED was mainly due to failure to take medications $(47.2 \%)$, followed by adverse drug reactions $(24.5 \%)$ and drug overdose $(11.3 \%)$. The most common drugs associated with DRPs were insulin, antiasthmatics, chemotherapeutic agents, warfarin, oral hypoglycemic and antihypertensive agents [9].

In Saudi Arabia, clinical pharmacy practice is in the process of being instituted in many public and private hospitals. In most of such hospitals, individuals with Bachelor of Pharmacy (B.Pharm) degree holders are engaged in conventional pharmacy practice; however, Pharm-Ds, who trained in direct patient care have recently been joining the services of these hospitals. At the moment, no hospital in the eastern region of Saudi Arabia, or perhaps in the country as a whole, has engaged a clinical pharmacist in a patient care unit, especially the ED. This study aims to evaluate the attitudes and perceptions of medical doctors and nurses in ED about the role of the clinical pharmacist.

\section{METHODS}

A pilot study was conducted among the medical and paramedical staff at the Emergency Department (ED), Public Hospital, Al-Ahsa, Eastern Region, Saudi Arabia,. The duration of this study was from $1^{\text {st }}$ July to $20^{\text {th }}$ August 2010. The entire medical and paramedical staff in the ED were invited to participate in the study.

\section{Study instrument}

A self-developed 24-item questionnaire was used to assess the objectives of the study. The questionnaire was designed in line with that of previous studies conducted in this regard in other Arab countries, such as Kuwait [10]. The content validity of the questionnaire was established by professionals at the College of Clinical Pharmacy, King Faisal University, and the Departments of Public Health and 
Biostatistics, Public Hospital, Eastern Region, Al-Ahsa. Face validity was tested on ten respondents from the nursing school, Public Hospital, Eastern Region, Al-Ahsa. A reliability scale was applied and the internal consistency of the questionnaire was measured using Cronbach's Alpha which gave a value of 0.58 .

The questionnaire had four sections. The first section consisted of nine items that mainly focused on the demographic information of the respondents, their experience and current position in the hospital. Section two explored medical and paramedical staff knowledge about Pharm-D degree and clinical pharmacy. Five questions were included in this section and they assessed the respondents' awareness of the Pharm-D degree and the professional practice of clinical pharmacy. This section also inquired about the availability of a clinical pharmacist in the respondents' hospital and whether a clinical pharmacist is the same as a hospital pharmacist. Section three mainly explored the level of interaction between the ED staff and the pharmacist. Respondents were asked how often they interacted with the pharmacist in the hospital setting and the reason for such interaction. The last section assessed ED staff's attitude toward the role of clinical pharmacists in EDs. Eight subitems were included in this section, and a three-item Likert scale (Agree, Disagree, Don't Want to Disclose) was used to measure the response.

\section{Ethical considerations}

A written consent was obtained from the respondents for their participation; furthermore, formal permission to conduct this study was requested from the head of the ED. Any questions that might disclose the identity of any respondents were avoided.

\section{Data analysis}

All the responses were coded, and descriptive statistics were applied using the Statistical Package for Social Science Students (SPSS 13) ${ }^{\circledR}$.

\section{RESULTS}

A total of 20 individuals present at ED during the study period were approached for their potential participation in this study. Of these, 16 expressed willingness to participate in the study, producing a response rate of $80.0 \%$. Six $(37.5 \%)$ of the respondents were doctors and the rest were nursing staff. The mean age (years) of the respondents was 37.0 (SD \pm 7.1 , range $24-47$ years). The majority of the respondents were foreign nationals. Detailed information about the respondents are listed in Table 1.

Table 1: Demographic profile of respondents

\begin{tabular}{|c|c|}
\hline Demographics & $\mathbf{N}(\%)$ \\
\hline \multicolumn{2}{|l|}{ Nationality } \\
\hline Saudi & $5(31.3 \%)$ \\
\hline Egyptian & $2(12.5 \%)$ \\
\hline Philippino & $7(43.8 \%)$ \\
\hline Indian & $1(6.3 \%)$ \\
\hline Syrian & $1(6.3 \%)$ \\
\hline \multicolumn{2}{|l|}{ Gender } \\
\hline Male & $6(37.5 \%)$ \\
\hline Female & $10(62.5 \%)$ \\
\hline \multicolumn{2}{|l|}{ Profession } \\
\hline Medicine & $6(37.5 \%)$ \\
\hline Nursing & $10(62.5 \%)$ \\
\hline \multicolumn{2}{|l|}{ Qualification } \\
\hline MBBS & $5(31.3 \%)$ \\
\hline MBBS+FCPS & $1(6.3 \%)$ \\
\hline BSc Nursing & $10(62.5 \%)$ \\
\hline \multicolumn{2}{|l|}{$\begin{array}{l}\text { Country of education } \\
\text { Egypt }\end{array}$} \\
\hline India & $2(12.5 \%)$ \\
\hline Philippine & $1(6.3 \%)$ \\
\hline Saudi & $7(43.8 \%)$ \\
\hline Syria & $\begin{array}{c}5(31.3 \%) \\
1(6.3 \%)\end{array}$ \\
\hline \multicolumn{2}{|l|}{ Job experience } \\
\hline 1-2 Years & $3(18.8 \%)$ \\
\hline 3-5 Years & $3(18.8 \%)$ \\
\hline $6-10$ years & $6(37.5 \%)$ \\
\hline 11 years or more & $4(25.0 \%)$ \\
\hline \multicolumn{2}{|l|}{$\begin{array}{l}\text { Is this your first job } \\
\text { experience }\end{array}$} \\
\hline Yes & $5(31.3 \%)$ \\
\hline No & $11(68.8 \%)$ \\
\hline \multicolumn{2}{|l|}{ Current position } \\
\hline Registrar & $1(6.3 \%)$ \\
\hline Senior Registrar & $2(12.5 \%)$ \\
\hline Senior Nurse & $5(31.3 \%)$ \\
\hline Medical Officer & $1(6.3 \%)$ \\
\hline Staff Nurse & $5(31.3 \%)$ \\
\hline Staff Physician & $1(6.3 \%)$ \\
\hline On training & $1(6.3 \%)$ \\
\hline
\end{tabular}


Table 2: Respondents' views about clinical pharmacists and hospital pharmacists

\begin{tabular}{lcc}
\hline Statement & Yes & No \\
\hline $\begin{array}{l}\text { Do you have a clinical pharmacist in your hospital? } \\
\text { Doctor }\end{array}$ & $-*$ & $6(37.5 \%)$ \\
$\quad$ Nurse & $8(50.0 \%)$ & $2(12.5 \%)$ \\
$\begin{array}{l}\text { Hospital pharmacists and clinical pharmacists } \\
\text { are the same }\end{array} \quad$ & \\
$\quad$ Doctor & & $6(37.5 \%)$ \\
$\quad$ Nurse & $--^{*}$ & $2(12.5 \%)$ \\
$\begin{array}{l}\text { Clinical pharmacy is a new field and at the moment } \\
\text { there is no clinical pharmacist at this hospital } \\
\quad \text { Doctor } \\
\quad \text { Nurse }\end{array}$ & & \\
$\quad *(-)$ indicates no response & $6(37.5 \%)$ & $-*$ \\
\hline
\end{tabular}

Table 3: Emergency Department staff interactions with pharmacists

\begin{tabular}{|c|c|c|}
\hline Item & Doctor & Nurse \\
\hline \multicolumn{3}{|c|}{$\begin{array}{l}\text { How often do you interact with the pharmacist at your hospital } \\
\text { setting? (Choose one option only) }\end{array}$} \\
\hline Never & 1 & - \\
\hline When there is a complicated case & 2 & 5 \\
\hline Once a week & 1 & 2 \\
\hline Daily & 2 & 3 \\
\hline \multicolumn{3}{|l|}{ What was the reason for interacting with the pharmacist? } \\
\hline Queries about the availability of drugs & 2 & 1 \\
\hline Queries about drug alternatives & 1 & 2 \\
\hline Queries about drug dosage and route of administration & 2 & 6 \\
\hline Information about the side effects of the medication & - & 2 \\
\hline Information about drug interactions & 2 & 2 \\
\hline
\end{tabular}

\section{Information about Pharm-D program and clinical pharmacist}

Ten $(62.5 \%)$ members of the ED staff were aware of the professional Pharm-D degree, and $12(75.0 \%)$ disclosed that they had heard of a clinical pharmacist. A majority, i.e., $10(62.5 \%)$ affirmed that they have heard of clinical pharmacy from a friend or medical journal, while 6 (37.5\%) noted that they had worked with a clinical pharmacist. ED staff responses about the availability of a clinical pharmacist at their hospital and their perceptions of the differences between clinical pharmacy and hospital pharmacy are shown in Table 2

\section{Level of interaction with pharmacists}

Table 3 indicates that most of the respondents disclosed that they interacted with pharmacists only in the case of emergencies. Further exploration revealed that pharmacists are mostly consulted to discuss drug dosages and routes of administration.

\section{Medical staff attitudes toward the availa- bility and possible role of clinical pharmacist in EDs}

Overall, a positive attitude towards the availability of the clinical pharmacist in ED was seen. The majority, i.e., $13(81.3 \%)$ of 
Table 4: Medical and nursing staff attitude to the presence of and participation of clinical pharmacist in Emergency Department

\begin{tabular}{|c|c|c|c|c|}
\hline Statement & Profession & A & DA & $\mathbf{N}$ \\
\hline It would be more helpful if clinical pharmacists & Doctor & $5(31.3 \%)$ & $1(6.3 \%)$ & - \\
\hline were available full-time in ED & Nurse & $8(50.0 \%)$ & $2(12.5 \%)$ & - \\
\hline Patient care will be improved if the clinical & Doctor & $4(25.0 \%)$ & $2(12.5 \%)$ & - \\
\hline $\begin{array}{l}\text { pharmacist works the medical and nursing staff } \\
\text { in ED }\end{array}$ & Nurse & $6(37.5 \%)$ & $4(25.0 \%)$ & - \\
\hline Involvement of clinical pharmacists in patient & Doctor & $2(12.5 \%)$ & $4(25.0 \%)$ & - \\
\hline care will interfere with my work & Nurse & $4(25.0 \%)$ & $4(25.0 \%)$ & - \\
\hline Availability of the clinical pharmacist in ED will & Doctor & $1(6.3 \%)$ & $5(31.3 \%)$ & - \\
\hline $\begin{array}{l}\text { make the selection of appropriate therapy } \\
\text { more difficult }\end{array}$ & Nurse & $2(12.5 \%)$ & $8(50.0 \%)$ & - \\
\hline I would be willing to seek assistance from the & Doctor & $1(6.3 \%)$ & $5(31.3 \%)$ & - \\
\hline $\begin{array}{l}\text { clinical pharmacist in designing drug therapy } \\
\text { treatment plans for my patients }\end{array}$ & Nurse & $2(12.5 \%)$ & $8(50.0 \%)$ & - \\
\hline Clinical pharmacists are ideal professionals to & Doctor & $4(25.0 \%)$ & $2(12.5 \%)$ & - \\
\hline $\begin{array}{l}\text { help in reducing the chances of drug-related } \\
\text { problems that often occur in day-to-day } \\
\text { medical practice, particularly in ED }\end{array}$ & Nurse & $5(31.3 \%)$ & $5(31.3 \%)$ & - \\
\hline In ED, physician workload will be shared if & Doctor & $2(12.5 \%)$ & $2(12.5 \%)$ & - \\
\hline $\begin{array}{l}\text { clinical pharmacists are authorized to prescribe } \\
\text { for less complicated cases and ailments }\end{array}$ & Nurse & $2(12.5 \%)$ & $8(50.0 \%)$ & - \\
\hline Adherence to therapy will be higher if clinical & Doctor & $3(18.8 \%)$ & $3(18.8 \%)$ & - \\
\hline $\begin{array}{l}\text { pharmacists conduct the counseling sessions } \\
\text { for patients }\end{array}$ & Nurse & $5(31.3 \%)$ & $5(31.3 \%)$ & - \\
\hline
\end{tabular}

\section{DISCUSSION}

the medical and nursing staff agreed that it would be more helpful if clinical pharmacists were available on a full-time basis in the ED, and $10(62.5 \%)$ agreed that patient care would be improved if the clinical pharmacist worked with medical and nursing staff in ED. On the other hand, half of the respondents $(50.0 \%)$ believed that the presence of a pharmacist in ED would somehow interfere with their work. Detailed responses of the staff toward the availability of the clinical pharmacist in ED are shown in Table 4.

Unlike the handling of medication in the main health care site, medications in the ED are always ordered, dispensed, and administered in a state of urgency for a patient at risk. Most of the medication orders given in such a situation are verbal because of the nature of ED, including the need for immediate medical care [11]. Handling a case in ED is a challenge because, in most cases, physicians are not aware of the patient's complete medical information and the medicines are dispensed directly to the patient without any prescription review [11]. Due to the high-alert environment of ED, health care staff members frequently handle multiple patients; the lack of review of prescriptions [11] can result in the potential risk of a mix-up of certain IV fluids, inotropic agents, and sedatives [8] which, in turn, can cause adverse events that may be fatal. Often, these adverse events are not reported because of the lack of follow-up for ED patients. Too often, if an adverse event is highlighted or reported, then the health provider - not the system - is blamed [12].

Considerations given to designing a system that improves patient safety [13] may well avert or reduce many adverse events before they reach the patient $[14,15]$. An ideal health care system removes the flaws or gaps that 
give rise to errors; if an error occurs nevertheless, it should be detected before it reaches the patient [15]. Incorporating the role of the clinical pharmacist in ED or other health care settings can reduce the number of adverse events, as research has shown [16]. Despite this demonstrated improvement in patient care along with cost savings [17], the role of the clinical pharmacist is not yet well-accepted in the hospital setting [18]. A possible reason for this attitude may the limited interaction of nursing staff with pharmacists because they do not consider pharmacists to be adequately trained to participate in patient care [18].

Medical and nursing staff's perception of the role of the clinical pharmacist in ED in the present study is worthy of review. A majority of our respondents were willing to accept the availability of a full-time clinical pharmacist in ED and more than half agreed with the statement that clinical pharmacist involvement in the health care team at ED would be helpful in patient care. However, some respondents had differing opinions. A possible reason for this negative attitude is that these staff perceive that the pharmacist will complicate or interfere with their work. These findings are in agreement with findings elsewhere which also indicate there are barriers to the acceptance of the pharmacist in the health care team by nurses and physicians $[18,19]$.

Furthermore, the ED staff response on the role of the pharmacist in drug adherence by patients was moderate. Nearly half agreed that adherence to drug therapy would be improved if the pharmacist is involved in direct patient care, but a majority disagreed with giving prescription rights to clinical pharmacists even when only minor ailments are involved. The reason for this attitude is a potential issue for the future research in the region. Our finding in this regard is similar to those of Matowe et al who also reported physician reluctance to give prescription rights to pharmacists even when minor ailments are involved [10].
Our findings highlight the need for the Ministry of Health in Saudi Arabia to take the initiative to intervene to develop an environment where physicians and pharmacists can work closely [19]. Other ED staff members need an opportunity to observe the pharmacist effectively acting as a part of the patient care team to enable them appreciate the very important roles that pharmacists are capable of playing in ED [10].

\section{Limitations of the study}

The current study lacks sufficient information to firmly establish the reasons for different attitudes of medical staff members toward pharmacists' possible role in direct patient care. The probable reason may be the absence of a clinical pharmacist at the ER department, thus limiting interactions with other ED staff and reducing awareness of the potential role of clinical pharmacists in direct patient care $[18,19]$.

\section{CONCLUSION}

The findings of this study highlight the need to enhance the interaction between the medical and paramedical staff, on the one hand, and clinical pharmacists, on the other, in order to facilitate the participation of the clinical pharmacist in direct patient care. If this is not done now, the first generation of Doctor of Pharmacy (Pharm-D) graduates that are expected to emerge in Saudi Arabia in the near future will face tremendous challenges in their practice within the Saudi health care system.

\section{REFERENCES}

1. Society of Critical Care Medicine and the American College of Clinical Pharmacy. Position paper on critical care pharmacy services. Pharmacotherapy 2000; 20: 1400-1406.

2. Thomasset $K B$, Faris $R$. Survey of pharmacy services provision in the emergency department. $A m \mathrm{~J}$ Health Syst Pharm 2003; 60: 1561-1564.

3. Croskerry $P$, Sinclair $D$. Emergency medicine: $A$ practice prone to error? CJEM 2001; 3: 271-276. 
4. Kohn LT, Corrigan JM, Donaldson MS, Eds. To err is human: Building a safer health system. Washington, DC: National Academies Press; 2000. p 26.

5. American Hospital Association. Hospital statistics. Chicago: AHA; 2000.

6. Chin $M H$, Wang LC, Jin L, Robert $M$, Walter J, Hayley DC, Karrison TG, Michael PN, Miller A, Friedmann PD. Appropriateness of medication selection for older persons in an urban academic emergency department. Acad Emerg Med 1999; 6: $1232-1242$.

7. Brennan TA, Leape LL, Laird NM, Hebert L, Localio R, Lawthers AG, Newhouse JP, Weiler PC, and Hiatt $\mathrm{HH}$. Incidence of adverse events and negligence in hospitalized patients. Results of the Harvard Medical Practice Study I. N Eng J Med 1991; 324: 370-376.

8. Peth HA. Medication errors in the emergency department: A systems approach to minimizing risk. Emerg Med Clin North Am 2003; 21: 141158.

9. Al-Olah YH, Al Thiab KM. Admissions through the emergency department due to drug-related problems. Ann Saudi Med [serial online] 2008 [cited 2010 Aug 29]; 28: 426-429. Available from:

http://www.saudiannals.net/text.asp?2008/28/6/ $426 / 51671$

10. Matowe L, Abahussain EA, Al-Saffar N, Bihzad SM, Al-Foraih A, Al-Kandery AA (2006) Physicians' perceptions and expectations of pharmacists' professional duties in government hospitals in Kuwait. Med Princ Pract. 2006; 15(3): 185-189.
11. Paparella S, ENA's ED Safety Workgroup. Avoid verbal orders. J Emerg Nurs 2004; 30: 157-159.

12. Schenkel S. Promoting patient safety and preventing medical error in emergency departments. Acad Emerg Med 2000; 7: 1204-1222.

13. McNutt R, Abrams R, Hasler S. Why blame systems for unsafe care? Lancet 2004; 363: 913-914.

14. Reason J. Human error: models and management. BMJ. 2000; 320(18): 768-770.

15. Leape LL, Bates DW, Cullen DJ, Cooper J, Demonaco $H J$, Gallivan $T$, Hallisey $R$, Ives J, Laird N, Laffel G, Nemeskal R, Petersen LA, and ADE Prevention Study Group. Systems analysis of adverse drug events. ADE Prevention Study Group. JAMA 1995; 274: 3543.

16. Leape LL, Cullen DJ, Clapp MD, Burdick E, Demonaco HJ, Erickson Jl, Bates DW. Pharmacist participation on physician rounds and adverse drug events in the intensive care unit. JAMA 1999; 282: 267-270.

17. Bond CA, Raehl CL, Franke T. Clinical pharmacy services, pharmacy staffing, and the total cost of care in United States hospitals. Pharmacotherapy 2000; 20: 609-621.

18. Azher S, Hassali. MA , Izham MI \& Khan .TM (2009) A qualitative evaluation of nurses' perception towards the role of pharmacist in healthcare setup in Pakistan. HealthMed J 2009: 3(4): 7176

19. Azher S, Hassali MA, Ibrahim MIM. Doctors' Perception and Expectations of the Role of the Pharmacist in Punjab, Pakistan. Trop J Pharm Res 2010; 9 (3): 205-222. 